\title{
Numerical Analysis of the Effect of Friction during Forming of Tube with Differential Wall Thickness
}

\author{
Nasa Kawagoshi*, Shohei Tamura ${ }^{\dagger}$ and Takeshi Kawachi ${ }^{\dagger}$ \\ * Research \& Development, NIPPON STEEL CORPORATION \\ 20-1 Shintomi, Futtu-shi, Chiba 293-8511 Japan \\ E-mail: kawagoshi.7gn.nasa@jp.nipponsteel.com, web page: https://www.nipponsteel.com/ \\ $\dagger$ Research \& Development, NIPPON STEEL CORPORATION \\ 20-1 Shintomi, Futtu-shi, Chiba 293-8511 Japan \\ Web page: https://www.nipponsteel.com/
}

\begin{abstract}
Steel tubes with differential wall thickness are required to reduce the weight of automobiles. One of the forming processes of steel tubes with differential thickness is the ironing of the inner surface[1]. In the first process, the end of the steel tube is expanded. In the second process, the punch is pushed in and the inner surface of the steel tube is ironed. As a result, the steel tube with a wall thickness difference of $50 \%$ can be formed. In this report, the behaviour of the steel tube during forming and the possible forming condition were clarified using FEM (Finite Element Method) analysis.
\end{abstract}

Abaqus/Explicit was used for FEM analysis, and analysis was performed using an axisymmetric model. The friction coefficient between the steel tube and the punch $\mu_{\mathrm{P}}$ is 0.00 to 0.20 , and the friction coefficient between the die and the steel tube $\mu_{\mathrm{D}}$ is 0.15 to 0.25 . As a result of the analysis, it was found that the friction coefficient difference $\Delta \mu=\mu_{\mathrm{D}}-\mu_{\mathrm{P}}$ needs more than the threshold in order to form the steel tube with differential thickness. If $\Delta \mu$ is larger than the threshold, the steel tube is fixed at the expansion part, and the steel tube with differential thickness can be formed. On the other hand, if $\Delta \mu$ is smaller than the threshold, the expansion part is slipping during forming and the steel tube with differential thickness cannot be formed. This result suggests that the effect of the friction coefficient can be evaluated quantitatively using FEM analysis.

In the future, the effects of other influencing factors (punch and die shapes) will be investigated using FEM analysis.

\section{REFERENCES}

[1]S. Kajikawa. Tube Forming (2020) PLASTOS, 33 527-531 